\title{
ASO Visual Abstract: Weight Tracking as a Novel Prognostic Marker After Pancreatectomy
}

\author{
Jonathan J. Hue, MD ${ }^{1} \mathbb{D}$, Lee M. Ocuin, MD ${ }^{1}$, Ravi K. Kyasaram, MS $^{1}$, John Shanahan, BA ${ }^{1}$, \\ Goutham Rao, $\mathrm{MD}^{2}$, Luke D. Rothermel, MD, MPH ${ }^{1}$, John B. Ammori, MD ${ }^{1}$, Jeffrey M. Hardacre, MD ${ }^{1}$, \\ Jordan M. Winter, MD ${ }^{1}$, and Sarah C. Markt, ScD, MPH $^{3}$
}

${ }^{1}$ Division of Surgical Oncology, Department of Surgery, University Hospitals Cleveland Medical Center, Cleveland, OH; ${ }^{2}$ Department of Family Medicine, University Hospitals Cleveland Medical Center, Cleveland, OH; ${ }^{3}$ Department of Population and Quantitative Health Sciences, Case Western Reserve University School of Medicine, Cleveland, OH

Pancreatectomy for cancer is complicated by a similar degree of weight loss as benign indications. Weight loss was not associated with survival, however the ability to regain weight was associated with improved outcomes. Weight loss after weight recovery foreshadows recurrence (https://doi.org/10.1245/s10434-022-11325-6).

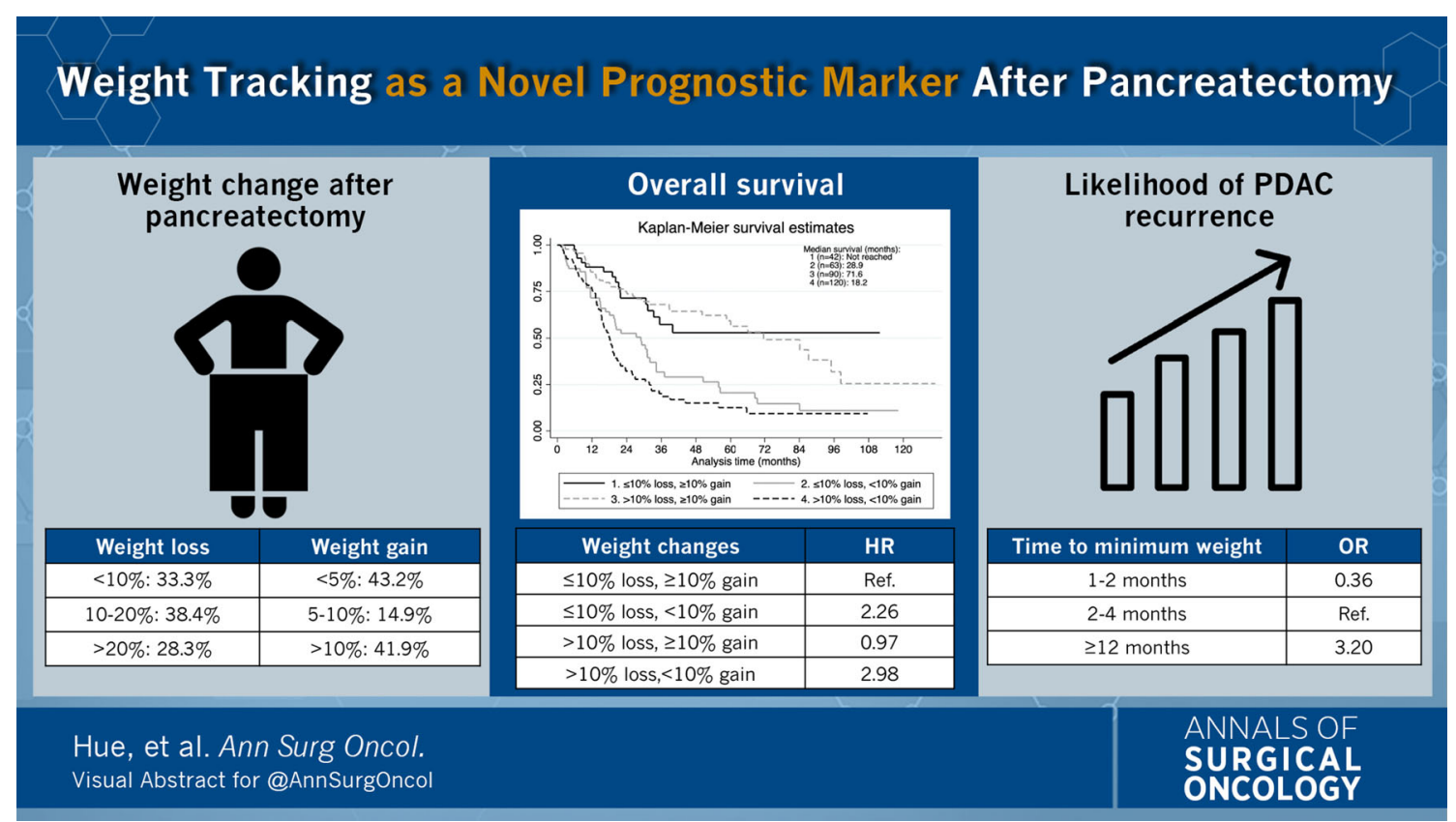

(C) Society of Surgical Oncology 2022

J. J. Hue, MD

e-mail: Jonathan.Hue@UHHospitals.org
DISCLOSURE Jonathan J. Hue, Lee M. Ocuin, Ravi K. Kyasaram, John Shanahan, Goutham Rao, Luke D. Rothermel, John B. Ammori, Jeffrey M. Hardacre, Jordan M. Winter, and Sarah C. Markt declare no potential conflicts of interest.

Publisher's Note Springer Nature remains neutral with regard to jurisdictional claims in published maps and institutional affiliations. 